\title{
Pumping Rate and Size of Demosponges-Towards an Understanding Using Modeling
}

\author{
Poul S. Larsen ${ }^{1, *(\mathbb{D})}$ and Hans Ulrik Riisgård ${ }^{2}$ (D) \\ 1 Department of Mechanical Engineering, Technical University of Denmark, 2800 Kgs. Lyngby, Denmark \\ 2 Marine Biological Research Centre, University of Southern Denmark, 5300 Kerteminde, Denmark; \\ hur@biology.sdu.dk \\ * Correspondence: psl@mek.dtu.dk
}

Citation: Larsen, P.S.; Riisgård, H.U. Pumping Rate and Size of

Demosponges-Towards an Understanding Using Modeling. J. Mar. Sci. Eng. 2021, 9, 1308. https:// doi.org/10.3390/jmse9111308

Academic Editors: Francesco

Tiralongo, Gioele Capillo and Armando Macali

Received: 15 October 2021

Accepted: 16 November 2021

Published: 22 November 2021

Publisher's Note: MDPI stays neutral with regard to jurisdictional claims in published maps and institutional affiliations.

Copyright: (c) 2021 by the authors. Licensee MDPI, Basel, Switzerland. This article is an open access article distributed under the terms and conditions of the Creative Commons Attribution (CC BY) license (https:// creativecommons.org/licenses/by/ $4.0 /)$.

\begin{abstract}
Filter-feeding sponges pump large amounts of water and contribute significantly to grazing impact, matter transport and nutrient cycling in many marine benthic communities. For ecological studies it is therefore of interest to be able to estimate the pumping rate of different species from their volume size or osculum cross-sectional area by means of experimentally determined allometric correlations. To help understand allometric data correlations and observed large variations of volumespecific pumping rate among species we developed a model that determines the pumping rate as a function of the size (volume) of a tubular-type demosponge described by 4 geometric length scales. The model relies on a choanocyte-pump model and standard pressure loss relations for flow through the aquiferous system, and density and pumping rate per choanocyte is assumed to be constant. By selecting different possibilities for increase of the length scales, which may also simulate different growth forms, we demonstrate that the model can imitate the experimental allometric correlations. It is concluded that the observed dependence of pumping rate on size is primarily governed by the hydraulics of pump performance and pressure losses of the aquiferous system rather than, e.g., decreasing density of choanocytes with increasing sponge size.
\end{abstract}

Keywords: sponges; choanocyte pump; pressure drop; growth; allometric scaling

\section{Introduction}

Filter-feeding sponges are one of the major components of marine benthic communities with a worldwide distribution [1]. Data on sponge size and pumping rates (filtration rates) are important for ecological studies in determining the grazing impact, matter transport and nutrient cycling of observed populations of sponges [2-6]. While sponge volume $(V)$ may be more difficult to measure or estimate in situ than the osculum cross-sectional area $(O S A)$, the latter has also been used as a correlation parameter [7], who used the following allometric relationships to characterize sponges:

$$
Q / V=a V^{b} ; Q=a_{1} O S A^{b 1} ; Q=a_{2} V^{b 2} ; U=a_{3} V^{b 3} ; O S A=a_{4} V^{b 4}
$$

where $Q / V$ denotes the volume-specific pumping rate, $Q$ the pumping rate, $V$ the sponge volume, OSA the osculum cross-sectional area, and $U$ the exhalant jet speed at osculum.

Demosponges are modular filter feeders that consist of one or several units, known as "aquiferous modules" [8-10]. An aquiferous module is a functional unit that draws ambient water through numerous inhalant openings (ostia) into an incurrent canal system by means of pumping units (choanocyte chambers, CC) that filter the water for nutrition and then eject it via an excurrent canal system to an atrial cavity and through a single exhalant opening (osculum) as a jet to the surrounding water.

Temporal variation in $O S A$ and pumping activity is a common feature among sponges [11-13]. Laboratory observation of the pumping activity of a multi-oscula sponge colony indicated that the sponge is sensitive to changes in water motion resulting in 
contractions of oscula, and further that a constriction of an individual osculum may cause closure of adjacent oscula and thus become a behavioral response of the entire modular sponge colony [14]. More recently, [15] compared relations between sponge size, OSA, exhalant jet speed, and pumping rate $(Q=O S A \times U)$ of single-osculum explants and of individual aquiferous modules of multi-oscula explants of the demosponge Halichondria panicea. The latter modules were identified by observing from which osculum surface administered dye emerged, and there was a fair agreement in results between the two types of modules. For both types, the pumping rate was a linear function of the modules' size (volume), and it was suggested [15] that this finding along with data from the literature on five demosponges [16] indicated that the density of choanocytes may be of the same order, independent of sponge size, although it is still unknown whether the choanocyte chamber density and its pumping rate vary through the ontology of long-lived species, especially for those that reach considerable size. Suggesting a constant density of pumping units (choanocytes) throughout any given sponge size, and assuming simple geometric (isometric) scaling $V \sim O S A^{3 / 2}$, [17] suggested a theoretical scaling of $Q \sim O S A^{3 / 2}$, which has been experimentally supported and confirmed in other studies, see Table 4 in [15]. However, [6,7] found in recent in situ studies on 20 demosponges that $Q$ on average increased allometrically $Q=a_{1} O S A^{b 1}$ with scaling exponent $b_{1} \approx 0.75,1.07$ and 0.67 (instead of the theoretical value of $b_{1}=3 / 2$ ), thus suggesting that the choanocyte density may not be constant but on the contrary decreases with sponge size.

A consequence of possible constant density and pumping rate of choanocytes is that $Q$ as a function of size $V$ is linear, i.e., $Q=a V$, and further that the volume-specific pumping rate is constant $Q / V=a V^{b}, b=0$, regardless of sponge size. This is supported by [13] and see Figure 5 in [15], but not by Table 5 in [6] that give negative $b$ values ranging from -0.2 to -0.7 . Further, [7] recently reported $b=-0.52$ for seven Red Sea sponge species and $b=-0.43$ for eight Caribbean species and therefore suggested that the theoretical considerations that explained the relationships observed by $[15,17]$ for relatively small sponge explants may not be "expected to hold for much larger and more static sponges". Thus, the scaling $b<1$ of power-law exponents may, according to [7], be explained by different aquiferous system structures and by choanocyte chamber densities, which may vary among species and with sponge size, and that the distribution of choanocyte chambers may vary in different parts of the sponge body. Further, according to [7], "as the sponge grows, the aquiferous system may become more complex" and thus a "constraint on the growth". Obviously, the relationships between sponge dimensions and pumping rate are not simple and vary among species. Specifically, the increase in pressure losses with increasing size in the aquiferous system structure may account for the observed scaling $b<1$ as discussed in the present study.

Here, as a supplement to the recent detailed summary of allometric data correlations by Table 4 in [7], we present available experimental literature data on volume-specific pumping rate $\left(Q / V=a V^{b}\right)$ of demosponges characterized by values of the exponent $b$. Furthermore, we present possible modelling of this relationship. Previous studies $[16,18]$ have determined the pressure losses for a specified pumping rate while the present approach, also using a model for the choanocyte pumps, gives the pumping rate. The way in which morphological length scales change with size increase affects pumping rate through changing pressure losses and may be an important factor and thus some help to explain observed trends. Thus, a key issue of the present study has been to establish trends in $Q / V$ versus $V$ based on use of pump-system characteristics.

\section{Available Data}

Over the years, there has been a considerable interest in measuring the pumping rate $(Q)$ of sponges as a function of their size (volume $V$ ). Results are often expressed as volumespecific pumping rate $(Q / V$, in units of $\mathrm{mL}$ water pumped per min per $\mathrm{mL}$ sponge $=\mathrm{mL}$ $\left.\min ^{-1} \mathrm{~mL}^{-1}=\min ^{-1}\right)$ versus volume $\left(V\right.$, in units of $\left.\mathrm{cm}^{3}\right)$, see Table 1 and Figure 1 for representative data. Reiswig Figure 1 in [2] found $Q / V$ to be essentially constant for 
increasing size of three specimens, likely because of constant density of choanocytes delivering the same volumetric flow rate, but specimens also showed a reduction of activity in largest sized individuals. For Halichondria panicea and Haliclona urceolus, Tables 1 and 2 in [19] measured a declining $Q / V$ with increasing size characterized by the negative power-law exponents of $b=-0.6$ and -0.39 of the correlation $Q / V=a V^{b}$, similar to $b=-0.35$ for large Xestospongia muta by [20]. The average of data from 14 species [21] and five species [16], on the other hand, showed $Q / V$ to be nearly constant $(b=-0.045$ and 0.051, respectively). Similar nearly constant $Q / V$ trends are seen in the data [17] for singe-osculum explants of $H$. panicea $\left(b=-0.038, b_{1}=1.45\right.$ and $\left.b_{2}=0.974\right)$, and in the data [22] for Cinachyrella cf. cavernose ( $\left.b=-0.071, b_{2}=0.929\right)$ where $b_{2}$-values (Equation (1)) near unity suggest constant pumping rate and density of choanocytes. Smaller single- and multi-oscular explants [15] showed different behaviors $(b=-0.19$ and 0.726 , respectively, and $b_{1}=1.22$ ), while the data of five Mediterranean species [6] showed consistent negative power-law exponents ( $b=-0.19$ to -0.49 ) over large ranges of increasing size and $b_{1}=0.75$. For 15 tropical species Figures S7 and 3 in [7], average values are suggested to be $b=-0.52$ and -0.43 , and $b_{1}=1.07$ and 0.67 , respectively. While it appears that other investigators based their data on total sponge volume, [13] explicitly used sponge tissue volume in

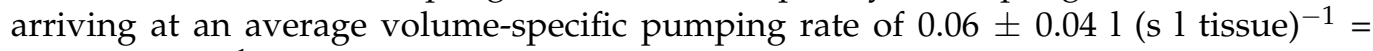
$3.6 \pm 2.4 \mathrm{~min}^{-1}$ for 274 large $X$. muta specimens, and the linear increase of pumping rate with size $\left(b_{2}=1.1\right)$ suggests $b \sim 0$.

Data on other allometric scaling correlations in Equation (1), as well as growth forms of species, are given by Table 4 in [7].

From the available data, it appears that the most fundamental feature of scaling laws of pumping rate is associated with the performance of the choanocyte pumps driving the flow against the pressure losses determined by the morphological structure of the aquiferous system of canals and restrictions, which are determined by several characteristic length scales [16]. Data on choanocyte density (Figure 2) show no clear trend for increasing sponge size, but all appear to be of the order of $10^{6} \mathrm{~mm}^{-3}$ within a factor of about 2 . Therefore, the modelling in next section provisionally assumes density of choanocytes to be constant.

Table 1. Data on volume-specific pumping rate of demosponges (in $\mathrm{mL}=\mathrm{cm}^{3}$ per $\min$ per $\mathrm{cm}^{3}$ of sponge $=\min ^{-1}$ ) versus sponge volume (in $\mathrm{cm}^{3}$ ) approximated by the power-law, $Q / V=a V^{b}$ $\left(\min ^{-1}\right)$. $V$-range gives $V_{\min }$ and $V_{\max }$ and $<Q / V>$ the algebraic average of data. Number (\#) refers to the plot of regression lines in Figure 1; \#8 and \#9a are single-osculum explants; \#9b individual modules of multi-osculum explants; \#15 and \#16 tropical sponges.

\begin{tabular}{ccccccc}
\hline$\#$ & Reference & Species & $\boldsymbol{a}$ & $\boldsymbol{b}$ & $\boldsymbol{V}$-Range $\left(\mathbf{c m}^{3}\right)$ & $\langle Q / V\rangle$ \\
\hline 1 & {$[2]$} & Mycale sp. & 15.1 & $\sim 0$ & 100 to 2300 & 14 \\
2 & $-“-$ & Verongia gigantea & 6.9 & $\sim 0$ & 600 to 10,000 & 3.3 \\
3 & $-“-$ & Tethya crypta & 9 & $\sim 0$ & 100 to 1700 & 11 \\
4 & {$[19]$} & Halichondria panicea & 8.18 & -0.6 & 4 to 17 & 2.7 \\
5 & $-“-$ & Haliclona urceolus & 3.96 & -0.39 & 0.6 to 45 & 2.5 \\
& {$[23]$} & H. panicea & 3.12 & -0.119 & 1.3 to 96 & 2.7 \\
& {$[21]$} & 14 species & 6.42 & -0.045 & 300 to 109,000 & 6.3 \\
& {$[20]$} & Xestospongia muta & 148 & -0.348 & 12,000 to 110,000 & 5.5 \\
& {$[13]$} & X. muta & & $\sim 0$ & 17.8 to 451,649 & 3.6 \\
6 & {$[14]$} & H. panicea & 2 & -0.82 & 1 to 12.5 & 6.1 \\
7 & {$[16]$} & 5 species & 3.77 & 0.051 & 1.9 to 449 & 6.7 \\
8 & {$[17]$} & H. panicea & 2.3 & -0.038 & 0.42 to 15.6 & 3.6 \\
$9 \mathrm{a}$ & {$[15]$} & H. panicea & 1.31 & -0.19 & 0.09 to 0.61 & 1.8 \\
$9 \mathrm{~b}$ & $-“-$ & H. panicea & 0.985 & 0.726 & 0.1 to 3.8 & 1.24 \\
& {$[22]$} & Cinachyrella cf. cavernose & 0.944 & -0.071 & 0.1 to 100 & 1.1 \\
10 & {$[6]$} & Dycidea avara & 17.88 & -0.22 & 1.5 to 148 & \\
11 & $-“-$ & Crambe crambe & 26.24 & -0.29 & 0.8 to 25 & \\
12 & $-“-$ & Petrosia ficiformis & 5.01 & -0.19 & 3.12 to 421 & \\
\hline
\end{tabular}


Table 1. Cont.

\begin{tabular}{ccccccc}
\hline$\#$ & Reference & Species & $\boldsymbol{a}$ & $\boldsymbol{b}$ & $\boldsymbol{V}$-Range $\left(\mathbf{c m}^{3}\right)$ & $\langle Q / V>$ \\
\hline 13 & $-“-$ & Chondrosia reniformis & 26.31 & -0.49 & 2.72 to 181 & \\
14 & $-“-$ & Agelas oroides & 30.39 & -0.70 & 2.98 to 440 & \\
15 & {$[7]$} & 7 species, Red Sea & 66.3 & -0.52 & 1 to 120 & \\
16 & $-“-$ & 8 species, Caribbean & 176 & -0.43 & 50 to 35,500 & \\
\hline
\end{tabular}

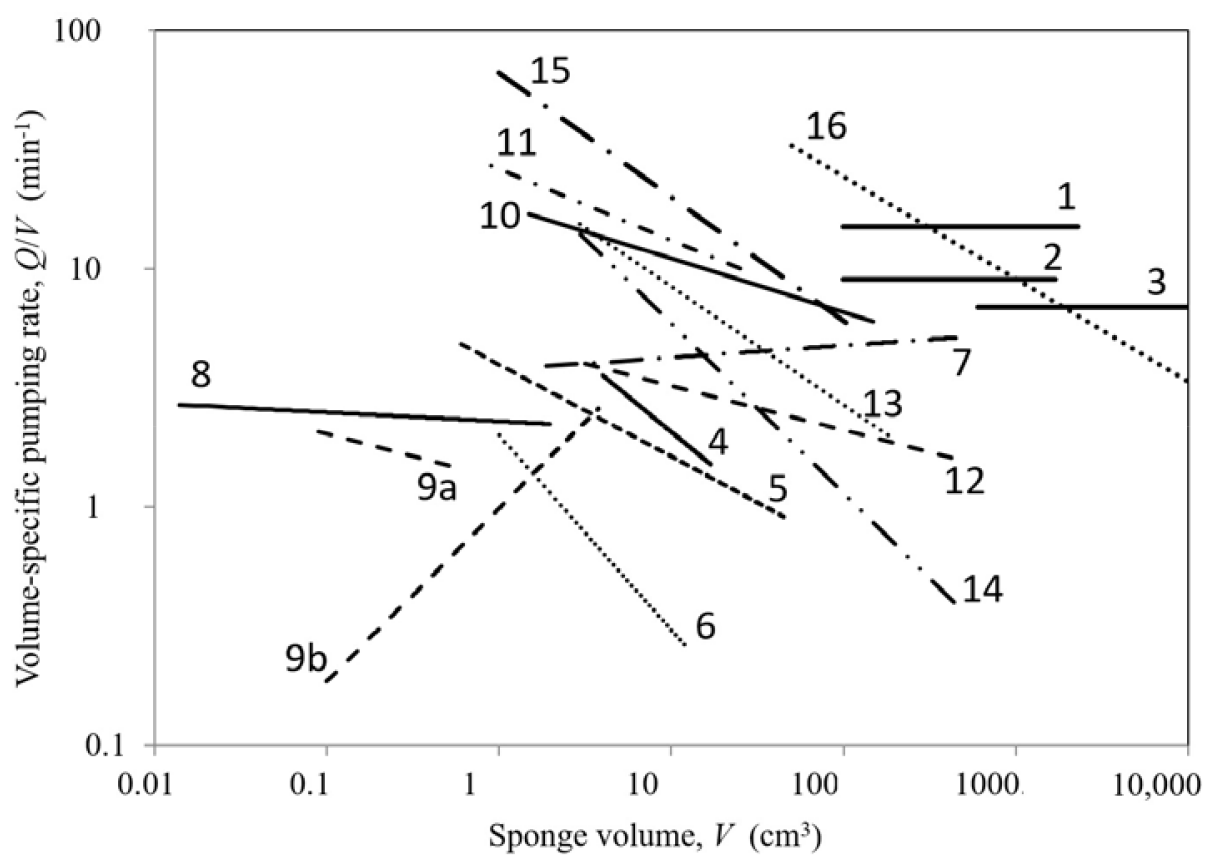

Figure 1. Power-law regression lines of experimental data showing trends. Numbers refer to the data of Table 1.

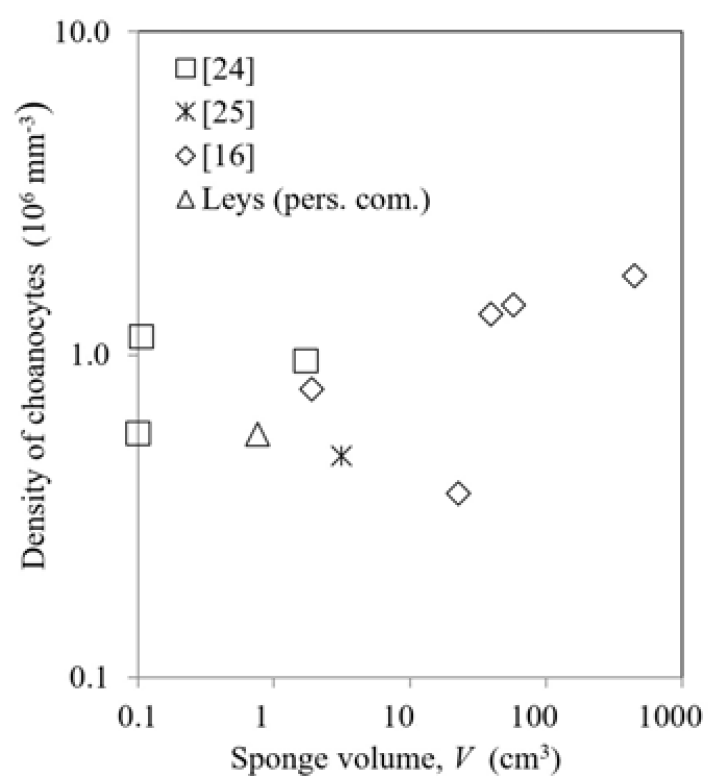

Figure 2. Density of choanocytes in various demosponge species studied by some authors [24,25].

\section{Modelling}

The purpose of the present modelling is to determine how pumping rate changes when pressure losses in the aquiferous system changes for increasing size of a demosponge due to various changes of morphological length scales (diameter, height, etc.) on the 
assumption of constant choanocyte density and to compare the results to available data. For a given configuration, the total pressure loss versus flow rate defines the so-called system characteristic. Furthermore, the pumping rate depends on how the basic pump unit, the choanocyte, or the group of these in a choanocyte chamber, responds to a given pressure to be delivered, which is given by the so-called pump characteristic [26]. Intersection of the system and pump characteristics determines the actual pumping rate and pump pressure.

Demosponges exhibit, according to [24], two extremes of external morphology: A low, solid, or encrusting form and an upright, hollow, or tubular form, and "all other types of habitus can be viewed as either slight modifications of these two dominant patterns or intermediates between these extremes." In the present study, we focus on the tubular sponge form to illustrate basic features and hydraulic consequences of increasing various morphological length scales. However, by suitable choice of model length scales, a tubular form may degenerate to a low and wide form with long incurrent and excurrent canals and thus imitate a massive or encrusting form.

For the model of a tubular sponge (Figure 3), whose morphology and size are given by four geometric length scales, model calculations give pumping rate as a function of sponge volume. Size increase in a sponge is determined by a genetically controlled ground plan (Bauplan) of morphological features common to each sponge species for how the individual length scales increase. One feature of this plan, for example, is revealed in the recorded data on the correlation Table 4 in [7] OSA $=a_{4} V^{b 4}$, which relates geometric dimensions. Later we shall use this as a constraint in the study of model performance. For each ground plan, the model calculations will show a trend of the volume-specific pumping rate versus size. Among possible scaling trends, we seek to identify the most likely ones to match a given observed trend.

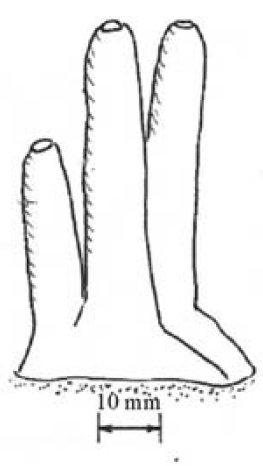

B

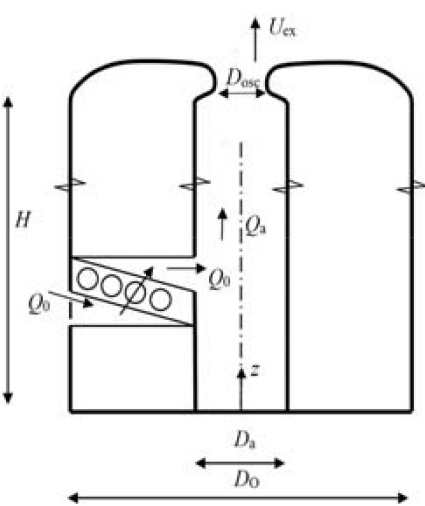

C

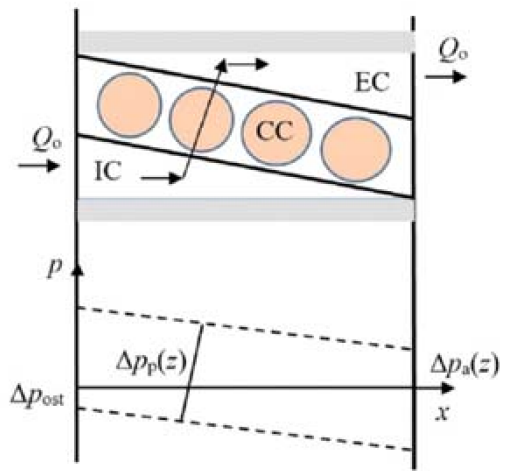

Figure 3. Model of tubular-type demosponge. (A) Haliclona permollis (redrawn from Figure 2 in [24]. (B) Schematic vertical section of model defined by four length scales, $H, D_{\mathrm{O}}, D_{a}, D_{\mathrm{osc}}$, which also define canal length $L=\left(D_{\mathrm{O}}-D_{a}\right) / 2$ and volume $V=(\pi / 4) D_{\mathrm{O}}{ }^{2} H$. The model shows flow rate $Q_{0}$ entering an incurrent canal (IC), driven by choanocyte pump units (CC), and leaving an excurrent canal $(E C)$ to the atrial cavity in which flow rate $Q_{\mathrm{a}}$ cumulates to the sponge pumping rate $Q$ that leaves the osculum as an exhalant jet with velocity $U_{\text {ex }}$ (C) Schematic detail showing the pressure variation through body of the sponge with inlet pressure loss $\Delta p_{\text {ost }}$ at ostia, pressure rise $\Delta p_{p}$ at choanocyte chamber pump, and prevailing pressure $\Delta p_{\mathrm{a}}$ at atrium at given height $z$ above the bottom of the sponge of height $H$.

Recognizing the structural differences in the geometrical form of different sponges, we consider three basic variants defined by the same four length scales, $H, D_{\mathrm{O}}, D_{\mathrm{a}}, D_{\mathrm{osc}}$ : (i) The slender tubular form (Figure $3 \mathrm{~A}$ ) where increasing size is due to increase primarily in height and less in diameter; (ii) the massive or encrusted form Figure S1H-L in [7], represented by a cylindrical form where increasing size is due to increase primarily in diameter and less in height, e.g., due to new aquiferous modules growing next to existing 
ones in multi-oscula sponges; (iii) the small cone-shaped single-osculum explants Figure 1 in [17] where increasing size is probably due to increase of both height and diameter. The individual modules of explants Figure 1 in [15] may be treated as the slender tubular form. For the tubular cases, volume and canal length are defined in Figure 3 as $V=(\pi / 4) D_{\mathrm{O}}^{2} H$ and $L=\left(D_{\mathrm{O}}-D_{a}\right) / 2$, respectively. For the cone-shaped case, $V=(\pi / 12) D_{\mathrm{O}}{ }^{2} H$ and the average canal length is approximated by $L=\left(D_{\mathrm{O}}-D_{a}\right) / 4$ and the outer surface area by $A_{\mathrm{S}}=\pi\left(H^{2}+D_{\mathrm{O}}{ }^{2} / 4\right)^{1 / 2} D_{\mathrm{O}} / 2$.

\subsection{Materials and Methods}

The model calculations are based on use of the computer modeled pump characteristic for a leucon-type demosponge Equation (2.13) for $C_{1}=0$ in [27] which leads to the nonlinear characteristic equation,

$$
\Delta p / \Delta p_{\max }=\left(1-Q / Q_{\max }\right)^{1 / 3}
$$

where $Q$ denotes the pumping rate for a given delivered pressure rise $\Delta p$ against and equal to the sum of pressure losses of the system represented by the flow through the sponge. The constants $\Delta p_{\max }$ and $Q_{\max }$ were determined from the data for morphological dimensions and pumping rate of the reference sponge Haliclona urceolus [19] as explained in Appendix A where Tables A1 and A2 summarize sponge parameters.

The pressure losses are calculated according to a previous model [19] now accounting also for the pressure loss of the atrium flow. In the model, choanocyte chambers (CCs) are imbedded in wall structures between incurrent (IC) and excurrent $(E C)$ canals such that these pump units act in parallel (Figure 3C). In the annular tissue structure of the tubular sponge, ambient water is drawn through ostia restriction into an IC canal by a row of CCs that discharge the flow into an EC canal that empties into the atrial cavity where the upward volume flow $Q_{\mathrm{a}}$ cumulates to leave ultimately through the osculum as an exhalant jet. There are several inlets (prosopyles) to a CC but only one outlet (apopyle). As part of the model, we assume that the observed decrease of diameter of ICs with length and with branching of ICs implies an approximately constant pressure gradient along the canal (see Appendix A.2 for a discussion). If CCs of the same pumping rate draw flow from points uniformly distributed over an $I C$ inner surface $(\mathrm{d} Q / \mathrm{d} x \sim-D)$ and the pressure gradient due to friction is constant $\left(Q \sim D^{4}\right)$, the diameter of the $I C$ would decrease as $D / D_{0}=(1-$ $x / L)^{1 / 3}$, where $L$ is the total length. Note also that a constant pressure gradient along IC and EC would imply that each one of the CCs in a row (Figure 3C) would face the same length of flow path, hence same total pressure drop and thus provide the same volume flow. The equations of the various pressure losses are detailed in Appendix A.

\subsection{Results}

First, let us ignore the effect that pressure losses have on reducing the pumping rate. In the search of scaling relations for volume-specific pumping rate versus volume (size) of a tubular sponge (Figure 3 ) we note that $V \sim D_{\mathrm{O}}{ }^{2} H$ and $Q \sim\left(D_{\mathrm{O}}{ }^{2}-D_{\mathrm{a}}{ }^{2}\right) H$ provided the pumping rate and density of choanocytes were constant in the structural annular volume. This scaling leads to the expression $Q / V \sim 1-\left(D_{\mathrm{a}} / D_{\mathrm{O}}\right)^{2}$, which for increasing $V$ implies a decrease, an increase, or no change depending on how $D_{\mathrm{a}} / D_{\mathrm{O}}$ changes with increasing $V$, irrespective of how $H$ changes. However, including the effect of flow reduction due to pressure losses will change the outcome, in most cases leading to decreasing pumping rate with increasing volume, as illustrated in the following examples. First, however, a simple matching of a linear pump characteristic with the pressure loss in a canal [28] leads to the relation $Q / V \sim 1 /\left(c+V^{2 / 3}\right)$ which gives $Q / V \sim V^{-2 / 3}$ for $c<<V$ and approaches $Q / V \sim$ constant for large values of the constant $c$ (see Appendix A.4 for the analysis). These results correspond to the range of trends shown by much of the data reported in Table 1.

Using the flow model described in Appendix A we first study isometric scaling of the geometry given by the four length scales $H, D_{\mathrm{O}}, D_{a}, D_{\mathrm{osc}}$ defined in Figure 3 . Introducing a scale factor $s f$ that takes values from 0.25 to 4 , we calculate how the volume-specific pumping rate $Q / V$ changes with the relative sponge volume $\left(V / V_{\text {ref }}\right)$ as the four length 
scales are changed by the factor $s f$ (Figure 4 upper curve). The volume given in Figure 3 will increase as $s f^{3}$, but the pumping rate will increase less (even though the choanocyte density is constant) because increased length of various canals increases pressure losses and thus reduce flow rate as dictated by the pump characteristic. Here, this implies a negative power-law exponent $b=-0.29$ which is similar to values displayed by some data in Table 1. Next, reducing the scaling of the osculum diameter to $D_{\mathrm{osc}} \sim S f^{1 / 2}$ changes the power-law exponent to $b=-0.57$ and $b_{1}=1.3$ (Figure 4 lower curve). These values should be compared to $b=-0.6$ and -0.39 for Halichondria panicea and Haliclona urceolis, respectively, of Table 1 (\#4 and \#5) and $b_{1}=1.45$ of the correlations of $Q=a_{1} O S A^{b 1}$ (not shown).

To see the effect of keeping some length scales constant, Figure 5A,B shows in detail how constant values of height or diameter, respectively, affects pumping rate for increasing sponge size when the remaining parameters are scaled. The figures show the existence of regions of increase, no change, and decrease in volume-specific pumping rate, corresponding to positive, zero, and negative values of the power-law exponent $b$. Increase occurs, for example, when diameters of atrium and osculum of a smaller sponge increase despite increasing size. Decrease occurs when length of canals and size increase.

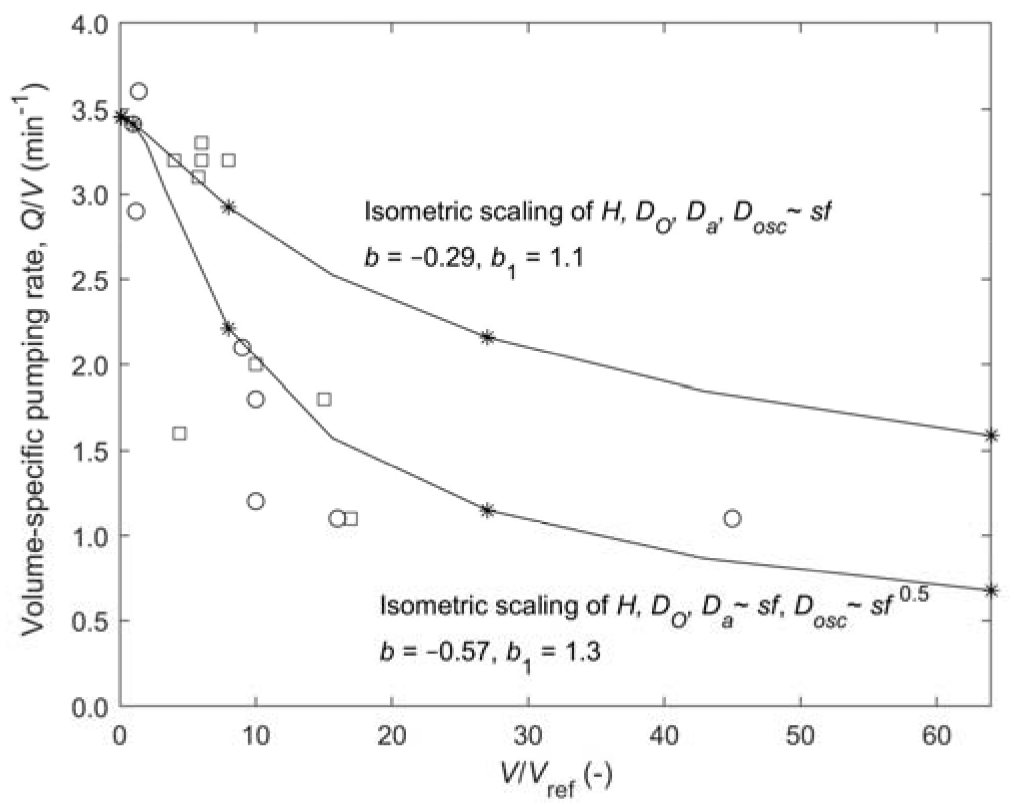

Figure 4. Tubular sponge flow model. Volume-specific pumping rate $(Q / V)$ versus normalized size $\left(V / V_{\text {ref }}\right)$ for the case of isometric scaling of $H, D_{\mathrm{O}}, D_{\mathrm{a}}, D_{\mathrm{osc}} \sim S f$ (upper curve) and for reduced scaling of osculum $D_{\mathrm{osc}} \sim s f^{0.5}$. (lower curve). Values of scale factor $s f=0.5,1,2,3$, and 4 give points marked by a star, and the reference sponge is marked by a circle. Shown values of power-law exponents may be compared to values $b=-0.6$ and -0.39 in Table 1 . Data for Halichondria panicea (\#4 of Table 1) are shown by squares and Haliclona urceolus (\#5) by circles. Shown values of power-law exponents may be compared to values $b=-0.6$ and -0.39 in Table 1 .

To model single-osculum explants, we choose as reference ID\#21 of Table 1 in [17] for which $Q / V=1.77 \mathrm{~min}^{-1}, b=-0.38$ (see Table 1 ), and $b_{1}=1.45$. For this reference, values of the four length scales are $H=13 \mathrm{~mm}, D_{\mathrm{O}}=15.6 \mathrm{~mm}, D_{\mathrm{a}}=1.1 \mathrm{~mm}$, and $D_{\mathrm{osc}}=15.6 \mathrm{~mm}$. Model results in Figure 6 suggest that isometric scaling, giving $b=-0.04$ and $b_{1}=1.4$, is in fair agreement with measured values. Single-osculum explants \#9a of Table 1 in [15] are of about the same size but with lower $Q / V$ and show somewhat stronger decrease with increasing size, $b=-0.19$ and $b_{1}=1.22$. 

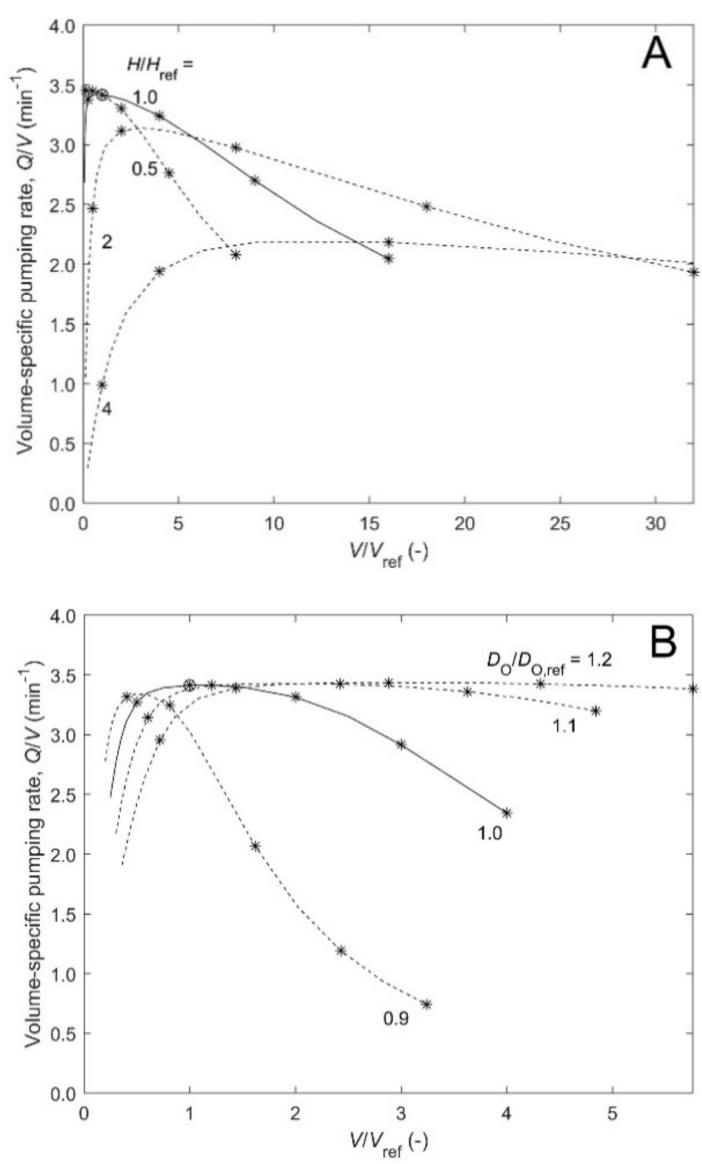

Figure 5. Tubular sponge flow model. Volume-specific pumping rate $(Q / V)$ versus normalized size $\left(V / V_{\text {ref }}\right)$. (A) Effect of increasing diameters by scale factor $s f=0.5$ to 4 for 4 values of fixed height. (B) Effect of increasing height by scale factor $s f=0.5$ to 4 for 4 values of diameters for fixed annular structure thickness $L=\left(D_{\mathrm{O}}-D_{\mathrm{a}}\right) / 2$ at its reference values. Values at $s f=0.5,1,2,3$, and 4 are marked on each curve by a star. The reference case is marked by a circle on the full-line curve.

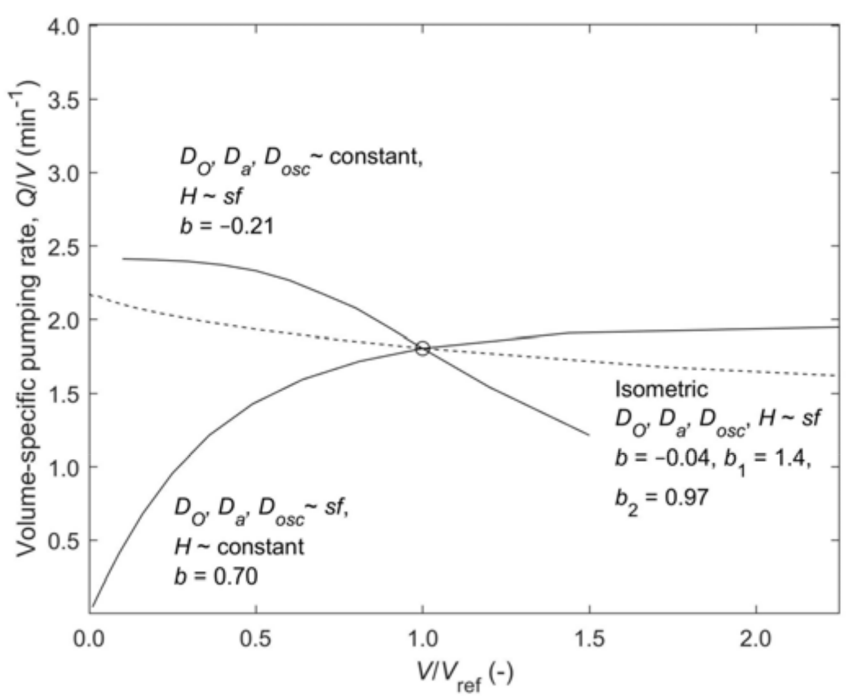

Figure 6. Sponge explant cone model. Volume-specific pumping rate $(Q / V)$ versus normalized size $\left(V / V_{\text {ref }}\right)$. The reference value (circle) corresponds to the geometry of ID\#21 of Table 1 in [17]. The scaling factor range $s f=0.1$ to 1.5 applied to height for constant diameters leads to a decreasing trend with increasing size, while applied to diameters at constant height it leads to an increasing trend (solid curves). Isometric scaling (dashed curve) leads to a weakly decreasing trend $(b=-0.04)$. 
The individual modules of multi-oscula explants of Halichondria panicea are tubular Figure 1 in [15] rather than cone-shaped, and the data show a strong increase in pumping rate versus size ( $\# 9 \mathrm{~b}$ of Table $1, b=0.726$ ) that is difficult to interpret. Size increase is probably associated with increase in both height and outer diameter, and if canal length $\left(L=\left(D_{\mathrm{O}}-D_{\mathrm{a}}\right) / 2\right)$ does not increase appreciably, pumping rate would tend to increase with size.

For demosponges of massive or encrusting form with several oscula, hence composed of several aquiferous modules, such as many of the species \#10-14 of Table 1, the structure and canal system is not well known. During growth, we imagine a first module can be treated as tubular until it reaches its maximal size and a new module starts to grow adjacent to the first one. Ref. [10] states that "Among encrusting demosponges new modules arise at the periphery and often result in the formation of very large sheets bearing more than 50 oscula". As new modules are added, the free surface area available to each module for inflow through ostia and incurrent canals is steadily being reduced which may imply that canals become longer which in turn causes a relative reduction in pumping rate of all modules such that $b<0$. Such volume increase during growth may be approximated by the tubular model in a phenomenological way by a scaling with little increase in height, large increase of outer diameter and canal lengths, and with an increase in osculum diameter, that reflects increasing number of oscula and pumping rate.

Finally, it is of interest to see how the model performs when using some experimentally determined scaling data relating to morphology. Here we consider the correlation OSA $=a_{4} V^{b 4}$ with $a_{4}=9.42$ and $b_{4}=0.6$ from Figure 5A in [7] for low-microbial-abundance, LMA, as constraint on the model parameters. Using the $O S A$-relation and the relations $V=(\pi / 4) D_{\mathrm{O}}^{2} H$ and $D_{\mathrm{osc}}=(4 O S A / \pi)^{1 / 2}$, determines $D_{\mathrm{osc}}$ as a function of $D_{\mathrm{O}}$ and $H$, leaving the three remaining length scales $H, D_{\mathrm{O}}, D_{\mathrm{a}}$ free to be scaled. As shown in Appendix $A$ Figure A1A, sample results for three scaling cases (scaling $H$, or diameters $D_{\mathrm{O}}, D_{\mathrm{a}}$ ) or all three parameters give resulting values of exponents $b, b_{1}$, and $b_{2}$. Values of $b(=-0.16,-0.2$ and -0.3) are comparable to those of Table 5 in [6] for LMA species, also listed as \#10-11 in Table 1 of the current paper. Similar calculations (Appendix A, Figure A1B) for high microbial-abundance HMA species $\left(a_{4}=3.81\right.$ and $\left.b_{4}=0.56\right)$ give $b=-0.2,-0.26$ and -0.37 . These results suggest that some or all observed trends of reduced $Q / V$ with increased $V$ could be explained almost entirely by the hydrodynamic effects of increasing pressure losses in aquiferous structures of increasing size. For more detail, Figure A2A-C shows the different contributions to the total pressure loss for the three cases of Figure A1A. As expected, according the model, as canal length increases for scaled diameters at constant height, pressure losses in incurrent and excurrent canals is the dominant contribution (by $50-85 \%$ of the total) which could represent encrusted and massive growth forms, but also for isometric scaling of height and diameter (by 20-75\%). For scaled height at constant diameter, on the other hand, pressure losses in the atrium flow dominate (by $26-75 \%$ ), which could represent the slender tubular growth form.

\section{Discussion}

The available literature data on pumping rate versus size of demosponges covers six decades of volumes from small single- and multi-oscula explants to large temperate and tropical sponges of various forms (Table 1 ). The morphological scaling is presented in terms of power-law regressions of volume-specific pumping rate versus volume $\left(Q / V=a V^{b}\right)$, which shows a variety of trends of positive, near-zero and-most often-negative exponents $b$ (Figure 1). Alternative scaling involving the parameters pumping rate $Q$, sponge volume $V$, osculum cross-sectional area $O S A$, and exhalant jet speed at osculum $U$ (Equation (1)) are summarized in [7].

Available data show that scaling laws of pumping rate appear to depend on species, temperate or tropical habitat, high or low microbial abundance (HMA or LMA) and growth form (tubular, vase, encrusting, massive). Possible other factors include density of choanocytes, seasonal variation in food availability and thus variation of the condition 
index (ratio of organic to inorganic matter [29], and height of sponge modules above the sea floor, as well as the morphological structure. The latter aspect is the focus of the present study because it is obvious that, for example, increased canal lengths with increased sponge size leads to increased pressure losses, hence to reduced pumping rate as dictated by the characteristic of the flagellum pump of choanocytes. To illustrate such effects, we developed a computation model that calculates the pumping rate as function of sponge size as specified by four length scales for a tubular model (Figure 3).

The model assumes a constant density of choanocytes because there is no clear trend in available data for its possible size dependence (Figure 2), but it could readily be modified to include any specified variation of density with size. The model (see Appendix A for details) also accounts for the pressure losses of the upward flow in the atrial cavity, which implies a decreasing pressure with increasing height facing the choanocyte pumps. However, to facilitate an algebraic solution we approximate the pressure in the atrium by its mean value such that all pumps deliver the same pressure rise and same volume flow. It is estimated that the error of this approximation amounts to a few percent for short atrial canals.

For realistic results, the model is based on the data for the "standard sponge" Haliclona urceolus [19] which is used as the reference sponge and for which the equation of pump characteristic was developed [27]. Reference values appearing in results are $V_{\text {ref }}=1.86 \mathrm{~cm}^{3}$, $(Q / V)_{\text {ref }}=3.41 \mathrm{~min}^{-1}$ and $Q_{\text {ref }}=6.34 \mathrm{~mL} \mathrm{~min}^{-1}$, and an isometric scaling with $s f=0.25$ to 4 will cover a range of sponge sizes from 0.029 to $119 \mathrm{~cm}^{3}$. The model results in Figure 4 for isometric scaling $\left(H, D_{\mathrm{O}}, D_{\mathrm{a}}, D_{\mathrm{osc}} \sim s f\right)$ and a modified scaling $\left(H, D_{\mathrm{O}}, D_{\mathrm{a}}, \sim s f\right.$, $D_{\text {osc } \sim S f^{1 / 2}}$, i.e., $O S A \sim s f$ ) are compared to the scarce experimental results for Halichondria panicea and H. urceolus ( $b=-0.6$ and -0.39 , respectively, of \#4 and \#5 of Table 1$)$. The case of modified scaling implies a reduced OSA, hence increased exit pressure loss and thus reduced pumping rates that seem to fit the data better, hence supporting the credibility of the model.

To help understand the response of model prediction to changes of the four length scales, Figure $5 \mathrm{~A}$ shows results for four values of constant height $(H)$ as diameters are scaled $\left(D_{\mathrm{O}}, D_{\mathrm{a}}, D_{\mathrm{osc}} \sim s f\right)$, and Figure $5 \mathrm{~B}$ shows results for four values of constant outer diameter $\left(D_{\mathrm{O}}\right)$ as other parameters are scaled $\left(H, D_{\mathrm{a}}, D_{\mathrm{osc}} \sim S f\right)$. The results show regions in which scaled increase of sponge volume may involve increase $(b>0)$, essentially no change $(b \sim 0)$, or decrease $(b<0)$ of volume-specific pumping rate. First, for some constant value of height $H$ (Figure 5A), scaled increase of all diameters implies $V \sim D_{\mathrm{O}}{ }^{2} H$ and $Q \sim\left(D_{\mathrm{O}}{ }^{2}-\right.$ $\left.D_{\mathrm{a}}{ }^{2}\right) H$, hence $Q / V \sim 1-\left(D_{\mathrm{a}} / D_{\mathrm{O}}\right)^{2} \sim$ constant if no pressure losses. This is consistent with an assumption of constant pumping rate and density of choanocyte pumps. However, for small diameters and large heights, such pressure losses are large primarily due to the flow along the atrial cavity and through osculum and these contributions decrease with increasing diameters such that $Q / V$ increases at first. Later, for larger diameters, the pressure loss in canals of increasing length, $L=\left(D_{\mathrm{O}}-D_{\mathrm{a}}\right) / 2$, becomes important and $Q / V$ levels off and begins to decrease, particularly for the smaller values of height. Such situations may represent encrusting or massive growth forms. Secondly, for some constant outer diameter $D_{\mathrm{O}}$ and constant width of the annular structure of a tubular sponge, which equals the canal length $L=\left(D_{\mathrm{O}}-D_{\mathrm{a}}\right) / 2$ (Figure $\left.5 \mathrm{~B}\right)$, scaled increase of height $H$ implies again $Q / V \sim$ constant, if there are no pressure losses. However, for small height, the pressure loss is primarily due to flow through the small osculum and this contribution decreases with increasing height of sponge and diameter of the osculum such that $Q / V$ increases at first. Later, for increasing height the increasing pressure loss in the atrium flow causes $Q / V$ to level off and begin to decrease, particularly at the smaller values of outer diameter. Such situations may represent slender tubular growth forms.

To study single-osculum explants, the tubular model was changed such that the four length scales could represent a cone-shaped geometry. The results in Figure 6 for three strategies show that scaled height at constant diameters leads to decreasing pumping rate during growth $(b<0)$, while scaled diameters at constant height gives increasing pumping rate $(b>0)$. Isometric scaling of height and diameters gives a weakly decreasing, almost 
constant pumping rate $(b=-0.041)$ that is close to the observation [17] $(b=-0.038)$. The correlation of the data on OSA versus volume [17] shows $D_{\mathrm{osc}} \sim V^{0.34}$ which is in good agreement with the isometric scaling, which implies $D_{\mathrm{osc}} \sim f s$ and $V \sim f s^{3}$, hence $D_{\mathrm{osc}} \sim V^{1 / 3}$. For the correlation $Q=a_{2} V^{b 2}$, the experiment and the model give almost identical trends, $b_{2}=0.97$ and 0.96 , respectively, supporting the hypothesis of constant choanocyte density. However, for magnitudes we should compare the complete correlations, which for the pumping rate of the experiment and the model are $Q_{\exp }=2.3 \mathrm{~V}^{0.97}$ and $Q_{\text {model }}=4.5 \mathrm{~V}^{0.96}$, respectively, and for the volume-specific pumping rate, $(Q / V)_{\exp }=2.3 \mathrm{~V}^{-0.038}$ and $(Q / V)_{\text {model }}=1.79 \mathrm{~V}^{-0.041}$. The discrepancies in magnitude could be due to underestimation of the model pressure losses, overestimation of the choanocyte pump performance, and the power-law fit to model results that show significant variation over the scaling range. Nevertheless, results strongly suggest that observed dependence of pumping rate on size of demosponges might primarily be governed by the hydraulics of pump and pressure losses of the aquiferous system.

We also explored the effect of constraining the scaling strategy by the geometrical correlation $O S A=a_{4} V^{b 4}$ obtained from experiments, leaving the three length scales $H, D_{\mathrm{O}}$, $D_{\mathrm{a}}$ free to be scaled (see Figure A1 in Appendix A). For both an LMA-type (e.g., Dysidea avara) and an HMA-type (e.g., Agelas oriodes), the best agreement of trend in terms of $b$-values appeared to be for scaled height at constant diameters, which would be expected for a tubular growth form. The two specimens are classified as encrusting and massive, but images in the literature (e.g. Figure S1 in [7]) show specimens and colonies with tubular growth form.

\section{Conclusions}

The present model determines the pumping rate as a function of size of a tubular demosponge described by four geometric length scales. The model relies on the availability of a choanocyte pump model and standard pressure loss relations for flow through restrictions and a canal system. Each choice of how the four length scales increase leads to a correlation between volume-specific pumping rate and size in terms of volume of a sponge which is compared to the published data on such allometric correlations that are summarized in Table 1. The trends of data, e.g., decrease or increase of pumping rate with increasing size (Figure 1), vary a great deal among species, their temperate or tropical habitat, high or low microbial abundance (HMA or LMA), and possibly other factors such as density of choanocytes and growth form, which affects the morphological structure. By selecting different possibilities for increase of the four length scales it has been demonstrated that the model imitates the experimental allometric correlations qualitatively (through the sign and magnitude of the exponent $b$ ) and to some extent also quantitatively (through the magnitude of the coefficient $a$ ). It is concluded that observed dependence of pumping rate on size of sponges might primarily be governed by the hydraulics of pump and pressure losses of the aquiferous system and not by, e.g., a reducing density of choanocytes with increasing size.

Author Contributions: P.S.L. developed the model and did the data analysis, H.U.R. contributed with biological input and text writing. All authors have read and agreed to the published version of the manuscript.

Funding: This research received no external funding.

Institutional Review Board Statement: Not applicable.

Informed Consent Statement: Not applicable.

Conflicts of Interest: The authors declare no conflict of interest. 


\section{Appendix A}

\section{Appendix A.1. Pump Characteristic of a Demosponge}

To quantify the pumping performance of a sponge we need a model for the basic pump unit, the choanocyte or the choanocyte chamber, or for the whole sponge, in terms of the pump characteristic $\Delta p_{\mathrm{p}}\{Q\}$, and the relation between volume flow $Q$ and pressure losses of the flow through the sponge, in terms of the system characteristic $\Delta p_{\mathrm{s}}\{Q\}$. Equating $\Delta p_{\mathrm{p}}$ to $\Delta p_{\mathrm{s}}$, determines the operating point $\Delta p_{\mathrm{op}}, Q_{\mathrm{op}}$.

For the pump, we use the results of the computational modeling of the leaky leucon pump Equation (2.13) for $C_{1}=0$ [27] that lead to the nonlinear characteristic equation,

$$
\Delta p / \Delta p_{\max }=\left(1-Q / Q_{\max }\right)^{1 / 3}
$$

where $\Delta p_{\max }$ and $Q_{\max }$ were determined from the data of the demosponge Haliclona urceolus [19], Table 1 and Figure 1c in [18]. Here, the figure gives the measured backpressure characteristic while the table gives the following parameters: size of specimen, length $L=32 \mathrm{~mm}$; outer and atrium diameters $D_{\mathrm{O}}=8.6 \mathrm{~mm}, D_{\mathrm{a}}=2.3 \mathrm{~mm}$, respectively, hence volume $V_{\mathrm{sp}}=1726 \mathrm{~mm}^{3}$; pumping rate and pressure drop at the operating point $Q_{\text {op }}=6 \mathrm{~mL} \mathrm{~min}^{-1}, \Delta p_{\mathrm{op}}=0.673 \mathrm{~mm} \mathrm{H}_{2} \mathrm{O}(=6.6 \mathrm{~Pa})$, respectively; estimated $C C$ density $n=12,000 \mathrm{~mm}^{-3}$; estimated number of choanocytes per $C C, n_{\mathrm{ch}}=80$. The measured value for the sponge, $\Delta p_{\max }=2.69 \mathrm{~mm} \mathrm{H}_{2} \mathrm{O}(=26.4 \mathrm{~Pa})$ ([18], Table 1 and Figure $1 \mathrm{c}$ therein) applies equally to the choanocyte chamber and the individual choanocyte when they all act in parallel. Because Equation (A1) implies a vertical tangent at $Q_{\max }$ we approximately set $Q_{\mathrm{max}, \mathrm{sp}} \approx 6 \mathrm{~mL} \mathrm{~min}^{-1}$ for the sponge. For Equation (A1) to apply to a choanocyte chamber, we calculate the corresponding pumping rate per $C C$ to $Q_{\max }=6 \times 10^{12} /(60 \times 1726 \times$ $12000)=4828 \mu \mathrm{m}^{3} \mathrm{~s}^{-1}$, and per choanocyte $Q_{\max , \mathrm{ch}}=60.3 \mu \mathrm{m}^{3} \mathrm{~s}^{-1}$.

\section{Appendix A.2. Simplified Model of Flow System}

Despite several studies of the dimensions of incurrent (IC) and excurrent (EC) canals and maps of morphometric data $[16,24,25]$, the details of actual branching aquiferous canal systems are complex and not fully understood. The branching, say from diameter $D_{1}$ to $D_{2}$ and $D_{3}$ at a bifurcation, should follow Murray's law Equation (14.6) in [30] to ensure constant wall shear stress, $D_{1}{ }^{\mathrm{e}}=D_{2}{ }^{\mathrm{e}}+D_{3}{ }^{\mathrm{e}}$ with $e=3$. On the other hand, assuming the pressure gradient of Poiseuille flow to be constant $\left(Q \sim D^{4}\right.$ and $\left.Q_{1}=Q_{2}+Q_{3}\right)$ leads to a diameter exponent of $e=4$. The detailed study by Figure 4 in [31] found that the exponent $e$ varied considerably, with a spectral distribution that peaked between 1 and 5 . For the present flow model, we assume $e=4$ such that the pressure gradient remains constant in the IC canal system that branches and thins because of outflow to choanocyte chambers as well as in EC canals that thicken due to inflow from chambers (Figure 3C). In this way it is likely that the total pressure loss through IC and EC canals experienced by flow through a given choanocyte chamber would be the same, hence the parallel coupled CC-pumps would all operate at the same pumping rate.

\section{Appendix A.3. Model Equations}

The present flow model for the sponge is based on a model [19] as derived for a specimen of the tubular demosponge Haliclona urceolus of dimensions: outer diameter $D_{\mathrm{O}}$, inner atrium diameter $D_{\mathrm{a}}$, height $H$ and osculum diameter $D_{\mathrm{osc}}$ (Figure 3B,C). The volume of sponge is $V_{\mathrm{sp}}=(\pi / 4) D_{\mathrm{O}}^{2} \mathrm{H}$, density of choanocyte chambers (CCs) is denoted $n$ and total pumping rate $Q$. Central to the flow model is the size and number of incurrent canals (IC) and the number of choanocyte chambers (CC) associated with each IC. An IC of mean diameter $D$ is surrounded by a wall structure of thickness $D_{\mathrm{cc}}$ in which choanocyte chambers $(C C \mathrm{~s})$ of diameter $D_{\mathrm{cc}}$ are imbedded at a spacing $l \sim D_{\mathrm{cc}}$ in a rectangular array over the inner IC surface area. For an IC canal of length $L$ this implies a number of $C C$ pumps $n_{\mathrm{cc}}=\pi D L / l^{2}$. The mean diameter $D$ is then determined by equating $n_{\mathrm{cc}}$ to the product of expected sponge average CC number density $n$ and the volume of the IC canal plus its wall, 
$V_{\mathrm{IC}}=(\pi / 4)\left(D+2 D_{\mathrm{cc}}\right)^{2} L, n_{\mathrm{cC}}=n V_{\mathrm{IC}}$. We obtain the number of IC canals from the count of $C C \mathrm{~s}, n_{\mathrm{IC}}=n V_{\mathrm{sp}} / n_{\mathrm{cc}}$, and the pumping rate per CC, which is the variable $Q$ in Equation (A1), becomes $Q_{\mathrm{cc}}=Q /\left(n_{\mathrm{IC}} n_{\mathrm{cc}}\right)$. To complete the model of the aquiferous canal system, we consider an IC canal of varying diameter $D(x)$ due to outflow to the $C C$ s along its wall, i.e., $\mathrm{d} Q / \mathrm{d} x=-\left(\pi D / l^{2}\right) Q_{\mathrm{cc}}$, and in which the pressure gradient of Poiseuille flow $-\mathrm{d} p / \mathrm{d} x=$ $\left(128 \mu / \pi D^{4}\right) Q(x)$ is furthermore assumed to be constant. This leads to a diameter variation $D(x) / D_{0}=(1-x / L)^{1 / 3}$, where $D_{0}$ denotes the inlet diameter at $x=0$ in the canal of length $L$, and a mean diameter of $D=3 / 4 D_{0}$. It is convenient to express the constant pressure gradient by its value at the inlet where the total flow rate is $Q_{0}=n_{\mathrm{cc}} Q_{\mathrm{cc}}=\pi D L / l^{2} Q_{\mathrm{cc}}$ and using also $D=3 / 4 D_{0}$ leads to $-\mathrm{d} p / \mathrm{d} x=\left(96 \mu / D_{0}{ }^{3}\right)\left(L / l^{2}\right) Q_{\mathrm{cc}}$, and a total pressure loss in the IC canal of

$$
\Delta p_{\mathrm{IC}}=\left(96 \mu / D_{0}{ }^{3}\right)(L / l)^{2} Q_{\mathrm{cc}}
$$

where $\mu\left(=0.00127 \mathrm{~Pa}\right.$ s at $\left.15^{\circ} \mathrm{C}\right)$ is the dynamic viscosity.

We now turn to the other pressure losses of flow through the sponge. According to Figure 2 in [24] there appears to be several, say $n_{\text {ost }}$, ostia apertures of diameter $D_{\text {ost }}$ leading the flow $Q_{0}=n_{\mathrm{cc}} Q_{\mathrm{cc}}$ into one IC canal. Treating each as an orifice Equation (4-29.2) in [32] gives,

$$
\Delta p_{\text {ost }}=\left(24 \mu / D_{\text {ost }}{ }^{3}\right) n_{\mathrm{cc}} Q_{\mathrm{cc}} / n_{\text {ost }}
$$

Given the fraction $f_{\text {ost }}$ of total outer surface area taken up by ostia, their number per IC inlet may be estimated from $n_{\text {ost }}=f_{\text {ost }}\left(D_{0} / D_{\text {ost }}\right)^{2}$. (For example, Table 2 in [24] gives $f_{\text {ost }}=30 \%$ and $f_{\mathrm{IC}}=10 \%$ for Haliclona permollis which for $D_{0}=100 \mu \mathrm{m}$ and $D_{\text {ost }}=20 \mu \mathrm{m}$

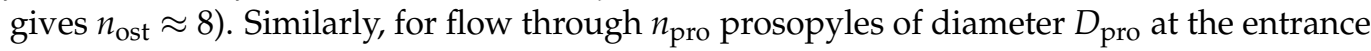
to CCs,

$$
\Delta p_{\text {pro }}=\left(24 \mu / D_{\text {pro }}{ }^{3}\right) n_{\mathrm{cc}} Q_{\mathrm{cc}} / n_{\text {pro }}
$$

Given $n_{\text {ch }}$ choanocytes per $C C$, the mean velocity of approach to the microvilli collar filter is $u=\left(Q_{\mathrm{cc}} / n_{\mathrm{ch}}\right) /\left(\pi D_{\mathrm{col}} L_{\mathrm{col}}\right)$, and the pressure drop across the array of cylindrical fibrils (microvilli) is estimated as in [19], using the theory of [33],

$$
\Delta p_{\mathrm{col}}=K \mu u / d_{\mathrm{mv}}
$$

where $K=8 \tau /\left(1-2 \ln \tau+\tau^{2} / 6\right), \tau=\pi d_{\mathrm{mv}} / b_{\mathrm{mv}}, d_{\mathrm{mv}}(=0.14 \mu \mathrm{m})$ is the fibril diameter and $b_{\mathrm{mv}}(=0.25 \mu \mathrm{m})$ the spacing.

From the apopyle of the CCs, flow enters EC canals, in which-depending on the architecture of the aquiferous canal system-there may be a pressure loss equal to that of Equation (A2) for the IC canal. Flow from many $E C$ canals cumulate in the atrial cavity to give the upward flow rate $Q_{\mathrm{a}}$ that varies with height $z$ and reaches the maximum $Q_{\mathrm{a}}(H)=$ $Q=n_{\mathrm{IC}} n_{\mathrm{cc}} Q_{\mathrm{cc}}$ at the osculum at height $H$. The number of $E C$ canals per unit of sponge height is $n_{\mathrm{IC}} / H$, each of which provides the volume flow $n_{\mathrm{cc}} Q_{\mathrm{cc}}$, hence the continuity equation of flow in atrium that describes the variation of $Q_{\mathrm{a}}$ becomes

$$
\mathrm{d} Q_{\mathrm{a}} / \mathrm{d} z=\left(n_{\mathrm{IC}} / H\right) n_{\mathrm{cc}} Q_{\mathrm{cc}}
$$

Because of the upward pressure decrease due to friction of the atrium flow the choanocyte chamber pumps deliver increasing flow with increasing height. This spatial variation gives rise to a complicated analysis, so to simplify the problem we approximate the total pressure loss in the atrial cavity flow by that of half the total flow acting over the full height,

$$
\Delta p_{\mathrm{a}}=1 / 2\left(128 \mu \mathrm{H} / \pi D_{\mathrm{a}}{ }^{4}\right) n_{\mathrm{IC}} n_{\mathrm{cc}} Q_{\mathrm{cc}}
$$

It follows that the flow from EC canals, hence from the $C C$ pumps, is approximated by a constant mean value $Q_{\mathrm{cc}}$. The average pump units at height $z=1 / 2 \mathrm{H}$ face a contribution that is one-half that of Equation (A7) while those below and above face more and less, respectively. Finally, the exit pressure loss at osculum is given by the kinetic energy $1 / 2 \rho U_{\mathrm{ex}}{ }^{2}$ of the exhalant jet, where the $U_{\mathrm{ex}}=n_{\mathrm{IC}} n_{\mathrm{cc}} Q_{\mathrm{cc}} /\left(\pi D_{\mathrm{osc}}{ }^{2} / 4\right)$, hence 


$$
\Delta p_{\mathrm{ex}}=1 / 2 \rho\left[n_{\mathrm{IC}} n_{\mathrm{cc}} Q_{\mathrm{cc}} /\left(\pi D_{\mathrm{osc}^{2}}{ }^{2} / 4\right)\right]^{2}
$$

The formulation of the problem is completed by inserting the sum of pressure losses, Equations (A2)-(A5), (A7) and (A8), into Equation (A1),

$$
\Sigma \Delta p=\Delta p_{\max }\left(1-Q_{\mathrm{cc}} / Q_{\max }\right)^{1 / 3}
$$

which is solved for $Q_{\mathrm{cc}}$ by a Newton iteration, and then all other quantities can be calculated, such as total and volume-specific pumping rates, $Q=n_{\mathrm{IC}} n_{\mathrm{cc}} Q_{\mathrm{cc}}$ and $Q / V$.

\section{Appendix A.4. Simple Scaling Model}

Consider the simple linear pump characteristic in terms of flow per choanocyte, $Q_{\mathrm{ch}}$

$$
Q_{\mathrm{ch}}=Q_{\mathrm{max}, \mathrm{ch}}\left(1-\Delta p_{\mathrm{ch}} / \Delta p_{\max , \mathrm{ch}}\right)
$$

where $Q_{\max , \mathrm{ch}}$ and $\Delta p_{\max , \mathrm{ch}}$ are constants. We assume constant density of choanocyte pumps acting in parallel and facing the same total pressure loss, $\Delta p_{\mathrm{ch}}$, of the flow through the aquiferous system. Expressing this pressure loss as that of flow rate $Q_{\text {can }}$ in a canal of length $L_{\mathrm{can}} \sim L$ of scale independent diameter gives the scaling $\Delta p_{\mathrm{ch}} \sim Q_{\mathrm{can}} L$. The number of canals is proportional to the sponge surface area $\sim L^{2}$ hence $Q_{\mathrm{can}} \sim Q / L^{2}$ and $\Delta p_{\mathrm{ch}} \sim Q / L$, where the total pumping rate is proportional to the volume $Q \sim Q_{\mathrm{ch}} V, V \sim L^{3}$ because of the constant choanocyte density. Using these relations to eliminate $Q_{\mathrm{ch}}$ and $\Delta p_{\mathrm{ch}}$ from Equation (A10) gives $Q / V \sim c_{1}\left(1-c_{2} Q / L\right)$ or

$$
Q / V \sim c_{3} /\left(c+V^{2 / 3}\right)
$$

where $c^{\prime}$ s are constants. Equation (A11) leads to $Q / V \sim V^{-2 / 3}$ for $c<<V$ and approaches $Q / V \sim$ constant for large values of the constant $c$, i.e., $b<0$ approaching $b \sim 0$, a range of trends shown by much of the data reported in Table 1.

Table A1. Nomenclature and sample values of the 'standard' sponge, Haliclona urceolis that serves as reference case $(C C=$ choanocyte chamber, $I C=$ incurrent canal, $E C=$ excurrent canal).

\begin{tabular}{cccc}
\hline Symbol & Description & Std. Sponge & Units \\
\hline$D_{0}=(4 / 3) D$ & IC inlet diameter & $0.136-0.313$ & $\mathrm{~mm}$ \\
$D$ & IC mean diameter & $0.102-0.235$ & $\mathrm{~mm}$ \\
$D_{\mathrm{a}}$ & Atrium diameter & 2.3 & $\mathrm{~mm}$ \\
$D_{\mathrm{cc}}$ & CC diameter & 0.030 & $\mathrm{~mm}$ \\
$D_{\mathrm{osc}}$ & Osculum diameter & 1.5 & $\mathrm{~mm}$ \\
$D_{\mathrm{ost}}$ & Ostia diameter & 0.0206 & $\mathrm{~mm}$ \\
$D_{\mathrm{pro}}$ & Prosopyle diameter & 0.005 & $\mathrm{~mm}$ \\
$D_{\mathrm{O}}$ & Sponge outer diameter & 8.6 & $\mathrm{~mm}$ \\
$H$ & Sponge height & 32 & $\mathrm{~mm}$ \\
$l$ & CC spacing in IC canal & $0.036-0.030$ & $\mathrm{~mm}$ \\
$L=1 / 2\left(D_{\mathrm{O}}-D_{\mathrm{a}}\right)$ & IC canal length & 3.15 & $\mathrm{~mm}$ \\
$n$ & Density of $C$ C in sponge & 12000 & $\mathrm{~mm}^{-3}$ \\
$n_{\mathrm{ch}}$ & No. of choanocytes per $C C$ chamber & 80 & - \\
$n_{\mathrm{cc}}=\pi D L / l^{2}$ & No. of CC along one IC canal & $778-2585$ & - \\
$n_{\mathrm{IC}}=n V_{\mathrm{sp}} / n_{\mathrm{cc}}$ & No. of IC (or $E C$ ) canals in sponge & $26,628-8013$ & - \\
$n_{\mathrm{ost}}$ & No. of ostia per IC canal inlet & $8-13$ & - \\
$n_{\mathrm{pro}}$ & No. of prosopyles in $C C$ & 3 & - \\
$Q_{0}$ & Flow rate at IC inlet & & \\
$Q_{\mathrm{a}}$ & Flow rate in atrial cavity & & \\
$Q_{\mathrm{cc}}$ & Pumping rate of $C C$ & 4760 & $\mu \mathrm{m}^{3} \mathrm{~s}^{-1}$ \\
$Q=n_{\mathrm{Ic}} n_{\mathrm{cc}} Q_{\mathrm{cc}}$ & Total pumping rate of sponge & 5.91 & $\mathrm{~mL} \mathrm{~min}^{-1}$ \\
$Q / V$ & Volume-specific pumping rate & 3.43 & $\mathrm{~min}^{-1}$ \\
$V_{\mathrm{IC}}$ & Volume of IC canal with wall & & \\
$V_{\mathrm{sp}}$ & Volume of sponge & 1726 & $\mathrm{~mm}^{3}$ \\
\hline
\end{tabular}


Table A1. Cont.

\begin{tabular}{cccc}
\hline Symbol & Description & Std. Sponge & Units \\
\hline$x$ & IC canal coordinate & & \\
$z$ & Vertical coordinate of atrium & & \\
\hline $\mathrm{Q}_{\max }$ & CC pump characteristic parameter & 4828 & $\mu \mathrm{m}^{3} \mathrm{~s}^{-1}$ \\
$\Delta p_{\max }$ & CC pump characteristic parameter & 26.4 & $\mathrm{~Pa}$ \\
\hline
\end{tabular}

Table A2. Pressure losses and pumping rate of present Haliclona urceolus model for the reference case with choanocyte chamber spacing $l=0.036 \mathrm{~mm}$ and counting $\Delta p_{\text {IC }}$ once, compared to those of ([19] Table 3 therein]).

\begin{tabular}{cccccc}
\hline & & \multicolumn{2}{c}{ Present Model } & \multicolumn{2}{c}{ Reference [19] } \\
\hline & & Pa & \% & Pa & \% \\
\hline Ostia & $\Delta p_{\text {ost }}$ & 0.78 & 14 & 0.37 & 6 \\
$I C / E C$ canal flow & $\Delta p_{\text {IC }}$ & 1.40 & 26 & 2.36 & 36 \\
Prosopyles & $\Delta p_{\text {pro }}$ & 0.30 & 6 & 1.13 & 17 \\
Collar filter & $\Delta p_{\text {col }}$ & 0.25 & 5 & 1.20 & 18 \\
Atrium flow & $\Delta p_{\text {a }}$ & 1.15 & 21 & 0 & 0 \\
Exahalent jet & $\Delta p_{\text {ex }}$ & 1.56 & 29 & 1.55 & 23 \\
Total pressure loss & $\Delta p_{\text {tot }}$ & 5.43 & 100 & 6.60 & 100 \\
\hline Pumping rate (mL min ${ }^{-1}$ ) & $Q_{\text {sp }}$ & 5.9 & & 6.0 & \\
\hline
\end{tabular}
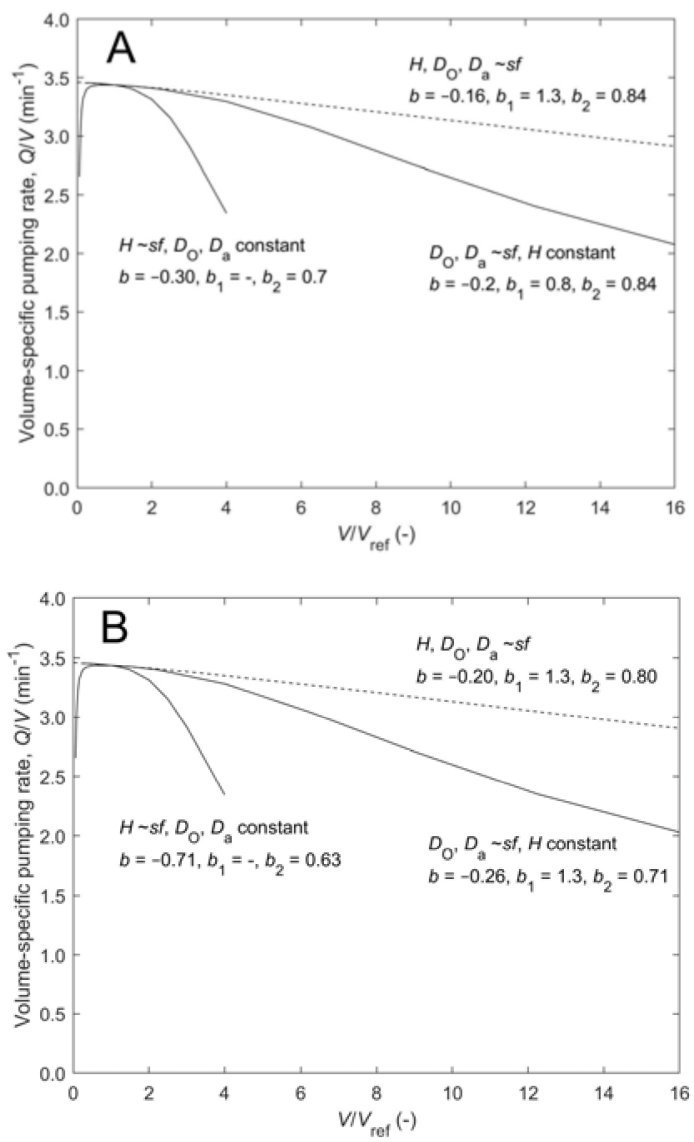

Figure A1. Tubular sponge flow model. Volume-specific pumping rate $(Q / V)$ versus normalized size $\left(V / V_{\text {ref }}\right)$ for 3 cases constrained by the experimental correlation $O S A=a_{4} V^{b 4}$. (A): $a_{4}=9.42$ and $b_{4}=0.6$ and (B): $a_{4}=3.81$ and $b_{4}=0.56$ from Figure 5A in [7]. Isometric increase of $H, D_{\mathrm{O}}, D_{\mathrm{a}}$ by scale factor $s f=0.5$ to 4 for 4 (dashed), $H$ constant, and diameters $D_{\mathrm{O}}, D_{\mathrm{a}}$ constant, respectively, (solid). Values of exponents $b, b_{1}$ and $b_{2}$ (see Equation (1)) of power-law fit for $s f>1.5$ shown. 

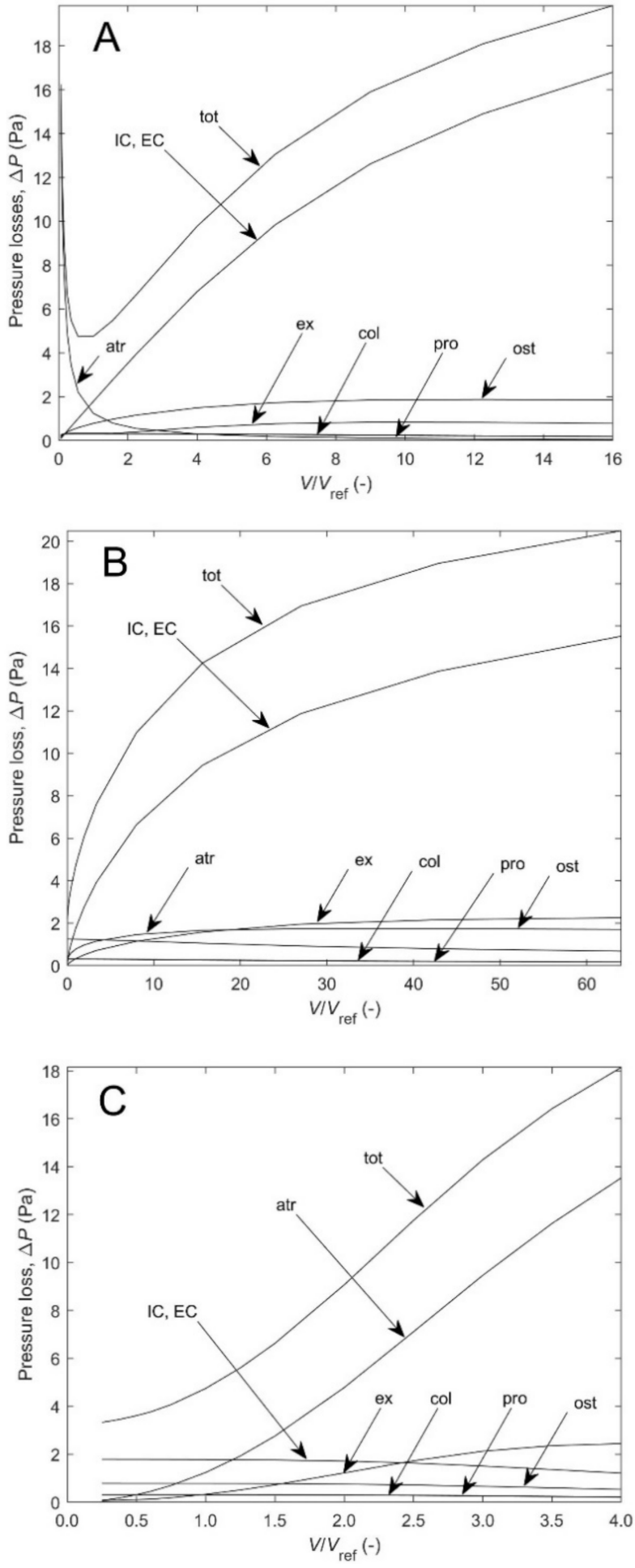

Figure A2. Tubular sponge flow model. Variation of total pressure loss and individual contributions as a function of scaled size increase for the 3 cases of Figure A1A. (A) $H$ constant, $D_{\mathrm{O}}, D_{\mathrm{a}}$ scaled by factor $s f=0.5$ to 4 , (B) $H, D_{\mathrm{O}}, D_{\mathrm{a}}$ scaled (isometric case), (C) $D_{\mathrm{O}}, D_{\mathrm{a}}$ constant, $H$ scaled. Pressure losses in incurrent and excurrent canals is the dominant contribution in (A,B) (by 50-85\% and 20-75\%, respectively, of the total pressure loss), while it is that of the atrium flow in (C) (by $26-75 \%$ of the total pressure loss). Pressure loss in ostia (ost), prosopyles (pro), incurrent and excurrent canals (IC, EC), collar (col), atrium (atr), exhalant jet (ex), and the sum (tot). 


\section{References}

1. de Voogd, N.J.; Alvarez, B.; Boury-Esnault, N.; Carballo, J.L.; Cárdenas, P.; Díaz, M.-C.; Dohrmann, M.; Downey, R.; Hajdu, E.; Hooper, J.N.A.; et al. World Porifera Database. 2021. Available online: http:/ / www.marinespecies.org/porifera (accessed on 10 November 2021).

2. Reiswig, H.M. Water transport, respiration and energetics of three tropical marine sponges. J. Exp. Mar. Biol. Ecol. 1974, 14, 231-249. [CrossRef]

3. Pile, A.J.; Patterson, M.R.; Witman, J.D. In situ grazing on plankton $<10 \mu \mathrm{m}$ by the boreal sponge. Mar. Ecol. Prog. Ser. 1996, 141, 95-102. [CrossRef]

4. Ribes, M.; Coma, R.; Gili, J.-M. Natural diet and grazing rate of the temperate sponge Dysidea avara (Demospongiae, Dendroceratida) throughout an annual cycle. Mar. Ecol. Prog. Ser. 1999, 176, 179-190. [CrossRef]

5. Coppari, M.; Gori, A.; Viladrich, N.; Saponari, L.; Canepa, A.; Grinyó, J.; Olariaga, A.; Rossi, S. The role of Mediterranean sponges in benthic-pelagic coupling processes: Aplysina aerophoba and Axinella polypoides case studies. J. Exp. Mar. Biol. Ecol. 2016, 477, 57-68. [CrossRef]

6. Morganti, T.; Ribes, M.; Yahel, G.; Coma, R. Size Is the Major Determinant of Pumping Rates in Marine Sponges. Front. Physiol. 2019, 10, 1474. [CrossRef]

7. Morganti, T.M.; Ribes, M.; Moskovich, R.; Weisz, J.B.; Yahel, G.; Coma, R. In situ Pumping Rate of 20 Marine Demosponges Is a Function of Osculum Area. Front. Mar. Sci. 2021, 8, 1-17. [CrossRef]

8. Ereskovskii, A.V. Problems of coloniality, modularity, and individuality in sponges and special features of their mor-phogeneses during growth and asexual reproduction. Russ. J. Mar. Biol. 2003, 29, 46-56. [CrossRef]

9. Fry, W.G. The sponge as a population: A biometric approach. Symp. Zool. Soc. Lond. 1970, 25, $135-162$.

10. Fry, W.G. Taxonomy, the individual and the sponge. Biology and Systematics of Colonial organisms. Syst. Ass. Spec. 1979, 11, 49-80.

11. Reiswig, H.M. In situ pumping activities of tropical Demospongiae. Mar. Biol. 1971, 9, 38-50. [CrossRef]

12. Savarese, M.; Patterson, M.R.; Chernykh, V.I.; Fialkov, V.A. Trophic effects of sponge feeding within Lake Baikal's littoral zone. 1. In situ pumping rates. Limnol. Oceanogr. 1997, 42, 171-178.

13. McMurray, S.E.; Pawlik, J.R.; Finelli, C.M. Trait-mediated ecosystem impacts: How morphology and size affect pumping rates of the Caribbean giant barrel sponge. Aquat. Biol. 2014, 23, 1-13. [CrossRef]

14. Riisgård, H.U.; Kumala, L.; Charitonidou, K. Using the F/R-ratio for an evaluation of the ability of the demosponge Halichondria panicea to nourish solely on phytoplankton versus free-living bacteria in the sea. Mar. Biol. Res. 2016, 12, 907-916. [CrossRef]

15. Kealy, R.A.; Busk, T.; Goldstein, J.; Larsen, P.S.; Riisgård, H.U. Hydrodynamic characteristics of aquiferous modules in the demosponge Halichondria panicea. Mar. Biol. Res. 2019, 15, 531-540. [CrossRef]

16. Ludeman, D.A.; Reidenbach, M.A.; Leys, S.P. The energetic cost of filtration by demosponges and their behavioural re-sponse to ambient currents. J. Exp. Biol. 2017, 220, 995-1007. [CrossRef] [PubMed]

17. Goldstein, J.; Riisgård, H.U.; Larsen, P.S. Exhalant jet speed of single-osculum explants of the demosponge Halichondria panicea and basic properties of the sponge-pump. J. Exp. Mar. Biol. Ecol. 2019, 511, 82-90. [CrossRef]

18. Larsen, P.S.; Riisgård, H.U. The Sponge Pump. J. Theor. Biol. 1994, 168, 53-63. [CrossRef]

19. Riisgård, H.U.; Thomassen, S.; Jakobsen, H.; Weeks, J.; Larsen, P.S. Suspension feeding in marine sponges Halichondria panicea and Haliclona urceolus:effects of temperature on filtration rate and energy cost of pumping. Mar. Ecol. Prog. Ser. 1993, 96, 177-188. [CrossRef]

20. Fiore, C.L.; Baker, D.M.; Lesser, M.P. Nitrogen Biogeochemistry in the Caribbean Sponge, Xestospongia muta: A Source or Sink of Dissolved Inorganic Nitrogen? PLoS ONE 2013, 8, e72961. [CrossRef]

21. Southwell, M.W.; Weisz, J.B.; Martens, C.S.; Lindquist, N. In situ fluxes of dissolved inorganic nitrogen from the sponge community on Conch Reef, Key Largo, Florida. Limnol. Oceanogr. 2008, 53, 986-996. [CrossRef]

22. Dahihande, A.S.; Thakur, N.L. Temperature- and size-associated differences in the skeletal structures and osculum cross-sectional area influence the pumping rate of contractile sponge Cinachyrella cf. cavernosa. Mar. Ecol. 2019, 40. [CrossRef]

23. Thomassen, S.T.; Riisgård, H.U. Growth and energetics of the sponge Halichondria panicea. Mar. Ecol. Prog. Ser. 1995, 128, 239-246. [CrossRef]

24. Reiswig, H.M. The aquiferous systems of three marine demospongiae. J. Morphol. 1975, 145, 493-502. [CrossRef] [PubMed]

25. Leys, S.P.; Yahel, G.; Reidenbach, A.; Tunnicliffe, V.; Shavit, U.; Reiswig, H. The sponge pump: The role of current induced flow in the design of the sponge body plan. PLoS ONE 2011, 6, e27787. [CrossRef]

26. Riisgård, H.U.; Larsen, P.S. Filter-Feeding in Marine Macro-Invertebrates: Pump Characteristics, Modelling and Energy Cost. Biol. Rev. 1995, 70, 67-106. [CrossRef]

27. Asadzadeh, S.S.; Larsen, P.S.; Riisgård, H.U.; Walther, J.H. Hydrodynamics of the leucon sponge pump. J. R. Soc. Interface 2019, 16, 20180630. [CrossRef] [PubMed]

28. Larsen, P.S.; Riisgård, H.U.; Asadzadeh, S.S.; Walther, J.H. Scaling in Filter-Feeding Sponges. In Proceedings of the ALSO Aquatic Science Virtual Meeting, 22-27 June 2021. Abstract 2899.

29. Lüskow, F.; Riisgård, H.; Solovyeva, V.; Brewer, J. Seasonal changes in bacteria and phytoplankton biomass control the condition index of the demosponge Halichondria panicea in temperate Danish waters. Mar. Ecol. Prog. Ser. 2019, 608, 119-132. [CrossRef]

30. Vogel, S. Life in Moving Fluids, 2nd ed.; Princeton University Press: Princeton, NJ, USA, 1994. 
31. Hammel, J.U.; Filatov, M.V.; Herzen, J.; Beckmann, F.; Jaap, A.; Kaandorp, J.A.; Nickel, M. The non-hierarchical, non-uniformly branching topology of a leuconoid sponge aquiferous system revealed by $3 \mathrm{D}$ reconstruction and morpho-metrics using corrosion casting and X-ray microtomography. Acta Zool. 2012, 93, 160-170. [CrossRef]

32. Happel, J.; Brenner, H. Low Reynolds Number Hydrodynamics; Springer: Singapore, 1981.

33. Tamada, K.; Fujikawa, H. The steady two-dimensional flow of viscous fluid at low reynolds numbers passing through an infinite row of equal parallel circular cylinders. Q. J. Mech. Appl. Math. 1957, 10, 425-432. [CrossRef] 